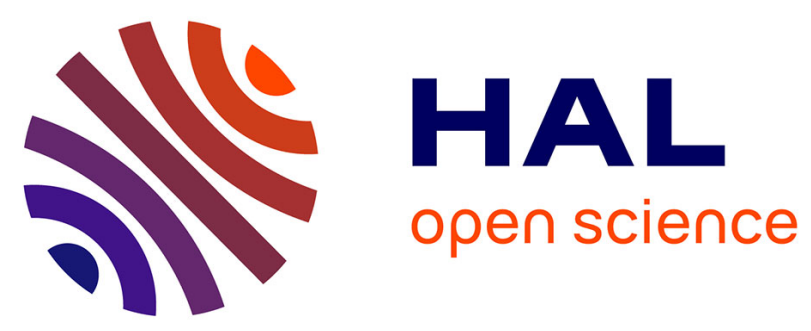

\title{
Heterodyne Optical Sampling for Picosecond Ultrasonics and Nanoscale Heat Transfer
}

Eric Mottay, Pierre Rigail, Robert Braunschweig, Christophe Pierre, Sébastien

Ermeneux, Clément Rossignol, Jean-Michel Rampnoux, Stefan A Dilhaire

\section{- To cite this version:}

Eric Mottay, Pierre Rigail, Robert Braunschweig, Christophe Pierre, Sébastien Ermeneux, et al.. Heterodyne Optical Sampling for Picosecond Ultrasonics and Nanoscale Heat Transfer. 2009 Conference on Lasers and Electro-Optics and 2009 Conference on Quantum electronics and Laser Science Conference, May 2009, Baltimore, United States. 10.1364/CLEO.2009.CMQ6 . hal-01840907

\section{HAL Id: hal-01840907 https://hal.science/hal-01840907}

Submitted on 26 Nov 2018

HAL is a multi-disciplinary open access archive for the deposit and dissemination of scientific research documents, whether they are published or not. The documents may come from teaching and research institutions in France or abroad, or from public or private research centers.
L'archive ouverte pluridisciplinaire $\mathbf{H A L}$, est destinée au dépôt et à la diffusion de documents scientifiques de niveau recherche, publiés ou non, émanant des établissements d'enseignement et de recherche français ou étrangers, des laboratoires publics ou privés. 


\title{
Heterodyne Optical Sampling for Picosecond Ultrasonics and Nanoscale Heat Transfer
}

\author{
Eric Mottay ${ }^{1}$, Pierre Rigail ${ }^{1}$, Robert Braunschweig $^{1}$, Christophe Pierre $^{2}$, Sebastien Ermeneux ${ }^{2}$, \\ Clement Rossignol $^{3}$, Jean-Michel Rampnoux ${ }^{3}$, Stefan Dilhaire ${ }^{3}$ \\ ${ }^{1}$ Amplitude Systemes, 6 allée du doyen Georges Brus - 33600 Pessac - France \\ 2 Alphanov, 351 Cours de la Liberation - 33400 Talence - France \\ ${ }^{3}$ Universite Bordeaux, 351 Cours de la Liberation - 33400 Talence - France
}

Stefan.dilhaire@u-bordeaux1.fr

\begin{abstract}
We present a novel ultrafast pump-probe system, allowing for a drastic reduction in acquisition time, typically a few tens of minutes for 20,000 frames. We present acoustic waves and heat transfer measurements in nanometric layers.
\end{abstract}

\section{Introduction}

Pump-probe techniques are widely used to measure events on time scales much shorter than the resolution of electronic detectors, and are applied in such diverse fields as ultrafast spectroscopy, photo-acoustics, TeraHertz imaging, etc. In ultrafast photoacoustics measurements for instance, a pump beam launches in the sample acoustic waves, which are detected by a second, temporally shifted probe beam. Typical detection methods rely on very small changes in the reflection coefficient of the sample surface, requiring an averaging of the signal to improve the signal to noise ratio. Traditional pump-probe methods use a mechanical delay line to shift the two pulses in the time domain, where each measurement point corresponds to a single mechanical position of the delay line. Although very efficient for small measurement ranges, extending this method in the hundreds of picoseconds or nanosecond lead to a very long acquisition time, and unpractical length for the delay line.

We present a new, compact detection system, using a compact dual-oscillator ultrafast laser system, specifically designed for pump-probe measurements over time scales as long $20 \mathrm{~ns}$, with a sub-picosecond resolution. This system does not use any mechanical delay line, and allows for extremely fast acquisition time.

\section{Experimental setup}

The system uses a new, compact diode-pumped ultrafast laser, incorporating two femtosecond oscillators, frequency locked to each other, with a small difference $(1 \mathrm{kHz})$ between the repetition frequency of the two lasers. Each pulse is therefore temporally shifted from the previous one without any mechanical adjustment. Since the repetition rate of the laser is very high $(50 \mathrm{MHz})$, a complete measurement can be done in a very short time (1ms). Since there is no need for delay line control, pump beam modulation, lock-in amplifier detection, the detection system is extremely simple, and only requires a high speed detector and averaging system. The pump and probe beam wavelength are slightly shifted in order to eliminate the residual pump signal on the detector. Averaging 10000 times the signal takes only $10 \mathrm{~s}$ allows to reach a signal to noise ratio close to $10^{-6}$.

\section{Results}

The first result shown in figure is the photothermal response of a $250 \mathrm{~nm}$ Tungsten film deposited on a silicon substrate. The signal exhibits a typical fast behavior coming from the electronic response of the material followed by a slow thermal decay. Superimposed with thermal background appear acoustic echoes showing the longitudinal acoustic wave reflected back and forth in the Tungsten film. The time of flight between successive echoes allows the determination of mechanical properties of the film while the thermal decay can be used to identify the thermal properties of nanomaterials. 


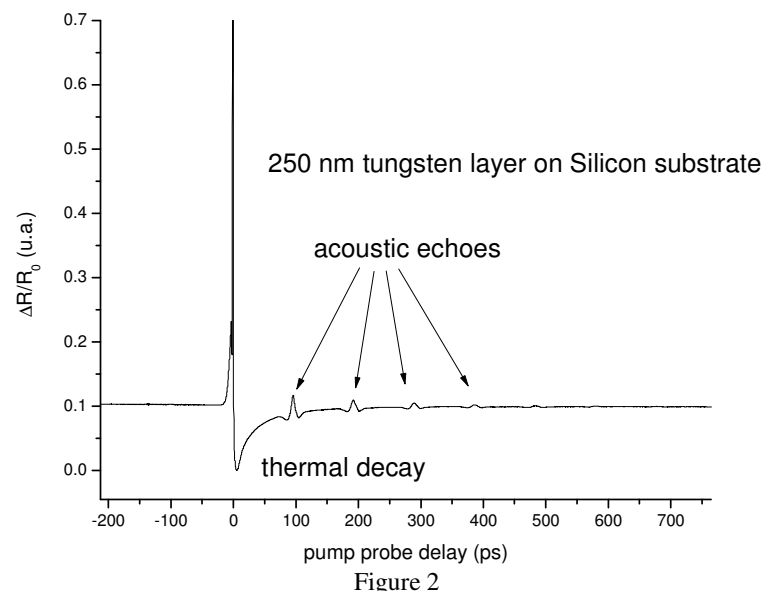

Once a point measurement is done on can scan the whole surface of interest of the material and reconstruct the film of the material response. Thus figure 1 is one of the pixel responses of the photothermal and photoacoustic movie. Frame rate is about 1 Tera images per second during $20 \mathrm{~ns}$. Acquisition time of the movie is a few ten of minutes. Figure 3 shows a frame of the photothermal and photoacoustic movie. One can easily see the thermal contribution to the signal giving rise, through thermoelastic coupling, to surface waves in the film.

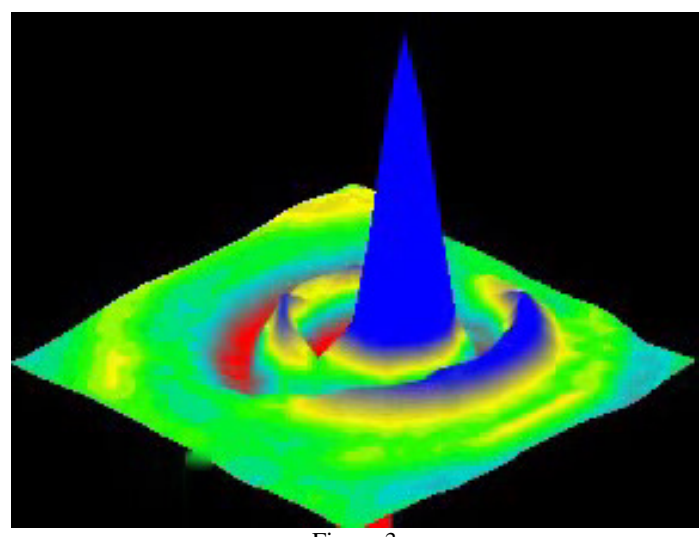

Figure 3

\section{Conclusion}

We have presented a new dual-source based optical sampling system designed for nanothermal applications which permits the imaging of the thermal and acoustic response of nano materials with a subpicosecond resolution. It is a breakthrough in nanomaterial thermal transport and ultrasonics experimental studies.

\section{References}

[1] Y. Ezzahri, S. Grauby, J.M. Rampnoux, H. Michel, G. Pernot, W. Claeys, S. Dilhaire, C. Rossignol, G. Zeng, A. Shakouri, "Coherent phonons in Si/SiGe superlattices", Phys. Rev. B 75, pp. 195309 (2007).

[2] Y. Ezzahri, S. Grauby, S. Dilhaire, J. M. Rampnoux, W. Claeys, "Cross-Plan Si/SiGe superlattice acoustic and thermal properties measurement by picosecond ultrasonics", J. Appl. Phys. 101, 013705 (2007).

[3] C. Rossignol, J. M. Rampnoux, T. Dehoux, S. Dilhaire, B. Audoin, "Picosecond ultrasonics time resolved spectroscopy using a photonic crystal fiber", Rev. Sci. Instrum. 77, 033101 (2006)

[4] Ezzahri,-Y.; Dilhaire,-S.; Grauby,-S.; Rampnoux,-J.-M.; Claeys,-W.; Zhang,-Y.; Zeng,-G.; Shakouri,-A.. Study of thermomechanical properties of Si/SiGe superlattices using femtosecond transient thermoreflectance technique. Applied Physics Letters 87, 1-3 (2005).

[5] C. Rossignol, J.M. Rampnoux, M. Perton, B. Audoin, S. Dilhaire, "Generation and detection of shear acoustic waves in metal submicrometric films with ultrashort laser pulses”, Physical Review Letters, 2005, 94(16): 166106/1-4 